\title{
Envolvimento parental na tarefa escolar
}

\author{
Ana Patrícia de Oliveira Fernandez \\ Universidade Federal do Pará - PA \\ Fernando Augusto Ramos Pontes \\ Universidade Federal do Pará - PA \\ Simone Souza Costa e Silva \\ Universidade Federal do Pará - PA \\ Mayara Barbosa Sindeaux Lima \\ Universidade Federal do Pará - PA \\ Cláudia Oliveira dos Santos \\ Universidade Federal do Pará - PA
}

\section{Resumo}

O objetivo deste trabalho foi investigar os sentimentos e percepções dos pais em relação ao envolvimento na tarefa escolar dos filhos. Foi utilizada pesquisa qualitativa, com ênfase na utilização do grupo focal. Participaram do estudo 12 responsáveis de adolescentes que cursavam o $7^{\circ}, 8^{\circ}$ e $9^{\circ}$ anos do Ensino Fundamental de uma escola privada. Os dados foram analisados através da análise de conteúdo. Os resultados indicaram que os pais veem a tarefa escolar como elemento constituinte da dinâmica das atividades escolares, a despeito dos sentimentos negativos que permeiam seu envolvimento na referida tarefa.

Palavras-chave: Pais-escola; lição de casa; percepção.

\section{Parental involvement in homework}

\begin{abstract}
In this work we investigate the feelings and perceptions of the parents towards their involvement in the homework of their children. A qualitative research was made with emphasis on the use of the focal group. The study had 12 participants : people responsible for teenagers who were in the 7th, 8th and 9th grade of the basic education from a private school. The data were analyzed by content analysis. The results indicated that the parents see the homework as an element which belongs to the dynamics of school activities, despite the negative feelings that permeate their involvement in the mentioned schoolwork.
\end{abstract}

Keywords: Parents; homework; perception.

\section{Envolvimiento parental en la tarea escolar}

\section{Resumen}

El objetivo de este estudio fue investigar los sentimientos y percepciones de los padres en relación al envolvimiento en la tarea escolar de los hijos. Se utilizó investigación cualitativa, con énfasis en la utilización del grupo focal. Participaron del estudio 12 responsables de adolescentes que cursaban el $7^{\circ}, 8^{\circ}$ y $9^{\circ}$ años de la Enseñanza Fundamental de una escuela privada. Los datos fueron analizados por intermedio del análisis de contenido. Los resultados indicaron que los padres ven la tarea escolar como elemento constituyente de la dinámica de las actividades escolares, a respecto de los sentimientos negativos que permean su envolvimiento en la referida tarea.

Palabras-clave: Padres; tarea escolar; percepcion. 


\section{Introdução}

Tradicionalmente, a tarefa escolar, também intitulada "para casa", "dever de casa" ou "lição de casa", é considerada um recurso pedagógico constituinte do processo de ensino-aprendizagem. A fixação, o reforço e a retenção de conteúdo estão entre os fatores que legitimam a referida atividade (Carvalho, 2004), favorecendo o desenvolvimento do senso de responsabilidade, da autonomia, da conscientização de esforço próprio para o alcance de metas (Epstein, \& Van Voorhis, 2001), bem como da autorregulação da aprendizagem (Zimmerman, \& Risemberg, 1997).

A família e a escola reconhecem a tarefa escolar como atividade fundamental para o sucesso acadêmico. Para Grolnick e Slowiaczek (1994), os efeitos positivos do envolvimento dos pais nas tarefas escolares dos filhos constituem um fator que contribui para o desenvolvimento educacional do aluno. Os pais, além de perceberem que seu envolvimento nas tarefas escolares é uma atitude positiva no desenvolvimento cognitivo de seus filhos, acreditam que este é um comportamento esperado pelos professores (Hoover-Dempsey, Battiato, Walker, Reed, \& Jones, 2001). A despeito dos pontos positivos associados ao envolvimento parental na tarefa escolar, alguns pesquisadores têm alertado sobre questões que podem comprometer sua eficácia (Carvalho, 2004; Paula, 2000; Resende, 2011).

Paula (2000) sugere que as campanhas promovidas pelas escolas em prol deste envolvimento podem acarretar efeitos nocivos, como sobrecarga de trabalho acadêmico para os alunos e uma concorrência desleal entre eles, pois nem todos terão o mesmo tipo de acompanhamento em casa por parte dos pais. Além do mais, Carvalho (2004) sustenta que a família acaba sendo vitimada pela imposição deste envolvimento, por conta da transferência de responsabilidade feita pela escola. O sentido do dever de casa para os estudantes, a divisão de trabalho entre família e escola, a quantidade de tarefas, a autonomia necessária para o aluno desenvolvê-la, também são aspectos que merecem ser discutidos, como aponta Resende (2011), na tentativa de desmistificar questões envolvidas na prática dessa atividade, em especial, no que diz respeito ao envolvimento dos pais.

A escola, ao propor a participação parental na tarefa escolar, parece não levar em conta as adversidades que subjazem no interior das famílias, tampouco procura adaptar as tarefas escolares para casa aos diversos estilos familiares existentes na atualidade (Carvalho, 2004). Esta diversidade de estilos familiares gera dificuldades para os pais, como terem de conciliar a falta de tempo decorrente do trabalho com o acompanhamento que os estímulos em torno da tarefa escolar sugerem, além de outros fatores comprometedores, como a qualidade da relação entre pais e filhos decorrente do estresse que envolve a realização da referida atividade (Carvalho, 2000; Paula, 2000; Resende, 2011).

Em geral, as dificuldades encontradas pela família em realizar a tarefa de casa têm sido pouco consideradas pela escola, assim como pela própria família. Este trabalho se justifica pela necessidade de discutir o aparente consenso diante da prescrição da tarefa, de modo a favorecer a compreensão de que sua existência e consequente repercussão no desenvolvimento do aluno estão atreladas a todas as adversidades enfrentadas pelas famílias contemporâneas.

\section{Objetivo do Estudo}

Este trabalho teve por objetivo investigar os sentimentos e percepções dos pais em relação ao seu envolvimento na tarefa escolar dos filhos.

\section{Método}

\section{Participantes}

Participaram deste estudo doze responsáveis por adolescentes. A amostra foi selecionada por conveniência, com participação voluntária de pais de alunos que cursavam o $7^{\circ}, 8^{\circ}$ e $9^{\circ}$ anos do Ensino Fundamental. Do total dos participantes, onze pais possuíam nível superior e um tinha nível médio. A renda mensal variou entre sete e 20 salários mínimos. A idade dos pais variou entre 34 e 45 anos. Dos doze participantes, onze eram mulheres e apenas um, homem.

\section{Ambiente}

A coleta foi realizada numa escola particular, de classe média, do Ensino Fundamental, tendo como prática acadêmica a realização da tarefa escolar. A participação da escola na pesquisa foi voluntária e a escolha se deu por conta da facilidade de acesso para a realização da coleta de dados.

\section{Instrumentos e técnicas}

Foram utilizados dois instrumentos de coleta: 1- um questionário estruturado com o objetivo de caracterizar os participantes da pesquisa, solicitando informações referentes a dados sociodemográficos, como sexo, idade, nível de escolaridade, estado civil e renda familiar; 2- entrevista de grupo, conhecida como "Grupo Focal", técnica que busca coletar os dados através da interação grupal (Charlesworth, \& Rodwell, 1997). Tal escolha se deu pela possibilidade de conhecer os sentimentos e percepções dos pais acerca do envolvimento na tarefa escolar dos filhos, já que esta é uma técnica que considera a visão dos participantes em relação a uma experiência ou a um evento, a partir de seus sentimentos, ideias e percepções. 


\section{Procedimento}

\section{Coleta de dados}

Após aprovação da análise pelo Comitê de Ética em Pesquisa com Seres Humanos da Universidade Federal do Pará, iniciou-se a coleta de dados, de acordo com a resolução de número 196/96 do Conselho Nacional de Saúde.

A pesquisa de campo teve início após a explicação dos objetivos junto à coordenadoria pedagógica da escola, que autorizou a realização do estudo. Os participantes foram indicados pela coordenadoria pedagógica do Ensino Fundamental, que disponibilizou trinta fichas cadastrais de alunos para que fossem feitos os primeiros contatos telefônicos com os responsáveis, juntamente com os boletins desses alunos. Dessas trinta fichas selecionadas, apenas dezesseis responsáveis aceitaram participar, enquanto os demais alegaram falta de tempo. Desses dezesseis, apenas doze pais compareceram, de fato, para participar do estudo, que foi realizado na própria escola. Uma das prerrogativas foi selecionar pais de alunos que tivessem rendimentos escolares situados nas faixas insuficiente $(0$ a 4,5$)$, regular (5,0 a 6.5$)$, bom $(7,0$ a 8,5$)$ e excelente $(9,0$ a 10,0$)$.

No primeiro encontro com os responsáveis selecionados foram realizadas as entrevistas para aplicação do questionário sociodemográfico. Para assegurar questões de ordem ética, foi apresentado aos pais o Termo de Consentimento Livre e Esclarecido, contendo informações acerca da natureza da pesquisa, bem como a garantia de sigilo das identidades dos participantes.

Após os procedimentos introdutórios iniciou-se a aplicação do grupo focal. Houve apenas uma sessão, pois diante da proposta de um segundo encontro, os pais alegaram falta de tempo e de disponibilidade. A sessão, que foi gravada e posteriormente transcrita, durou cerca de uma hora e trinta minutos. Além da moderadora que coordenou a sessão, a aplicação da técnica contou com uma auxiliar de pesquisa (estudante de graduação em Psicologia). Os pais foram incentivados a falar sobre os sentimentos que surgiram sobre o assunto no decorrer da discussão.

Os temas discutidos durante o grupo focal foram elaborados previamente e abordaram as seguintes questões: "O que vem à cabeça de vocês quando se pensa em tarefa escolar?"; "Como é a participação de vocês na vida escolar dos filhos?"; "Os filhos de vocês fazem a tarefa escolar? Como é que eles fazem? A que horas? É sempre no mesmo horário? Fazem sozinhos? Alguém ajuda? É preciso mandar?"; Vocês participam dessa atividade? Como?"; "Como se sentem participando?"; "O que vocês acham que os filhos pensam sobre a tarefa escolar?"; "Vocês sentem alguma dificuldade no acompanhamento das tarefas dos filhos? Quais?".

\section{Análise de dados}

Após transcrição do material coletado deu-se início à análise dos dados. Optou-se pela utilização da "Análise de Conteúdo", técnica que busca as partes significativas encontradas nas falas para constituir as unidades de sentido. Este processo indutivo contribui para a formação de categorias que emergem a partir dos dados (Bardin, 1995). Assim, foram criadas categorias que contemplavam os fenômenos encontrados, possibilitando as interpretações que deram significados às mensagens emitidas. Estas categorias agruparam-se em unidades de análise, as quais foram representadas por temáticas consideradas relevantes. Desse modo, foram construídas quatro dimensões ou unidades de análise, com seus respectivos agrupamentos de categorias, descritos a seguir.

1.Percepções dos pais acerca da funcionalidade do dever de casa, em que foram agrupadas as percepções dos pais acerca da justificativa dada para a aceitação do dever de casa, como tarefa legítima.

2.Percepção dos pais acerca do sentido que os filhos atribuem ao dever de casa: por meio dos relatos dos participantes, foram constatadas duas formas diferenciadas de como o dever de casa é concebido pelos adolescentes, o que culminou na construção de duas categorias de percepção de sentidos: Percepções positivas e Percepções negativas; e na categoria "Percepções positivas" foram incluídos relatos de responsáveis que demonstram que os filhos apresentam comportamentos caracterizados por boa vontade, tranquilidade, satisfação e interesse em realizar a tarefa; e na categoria "Percepções negativas" foram incluídos conteúdos de falas que expressam repulsa por parte dos adolescentes diante da realização da tarefa escolar e falta de iniciativa ou de estímulo.

3.Percepção dos pais em relação à participação na vida escolar dos filhos: dentro desta unidade de análise foram criadas duas categorias: "Participação Direta" e "Participação Indireta". Na categoria "Participação Direta" consideraram-se as falas cuja compreensão estivesse voltada à participação ativa nas atividades relacionadas à vida escolar, incluído aí o envolvimento com o dever de casa. A categoria "Participação Indireta" contemplou falas que viam a participação dos pais apenas como algo expresso por meio de atitudes de incentivo, estímulo e oportunidades facilitadoras do desempenho escolar, em vez de ações concretas de envolvimento na vida acadêmica dos filhos, como o envolvimento no dever de casa. 
4. Sentimentos dos pais acerca da realização do dever de casa: nesta unidade foram reunidos os sentimentos que a realização do dever de casa provocava nos pais. Dela emergiram duas categorias: "Contra a tarefa" e "Insegurança". A categoria "Contra a tarefa" foi compreendida por falas de pais que se posicionaram contrários à prática do dever de casa. A categoria "Insegurança" aglutinou falas que demonstraram sentimentos associados à falta de habilidades específicas relacionadas ao conteúdo acadêmico ministrado em sala de aula, inviabilizando a ajuda que a tarefa demanda. A despeito de que, no limite, tais categorias não são mutuamente excludentes, a categorização diferenciada aqui utilizada justifica-se por revelar variações de sentimentos gerados pelas demandas que o envolvimento dos pais no dever de casa suscita.

Vale ressaltar que, para correlacionar os sujeitos com suas características de forma a garantir seu anonimato e para facilitar a análise dos dados, os participantes foram identificados com nomes fictícios, seguidos de uma letra indicativa do rendimento escolar do filho, podendo ser "E" para excelente, "B" para bom, "R" para regular e "I" para insuficiente, como por exemplo: Ana-I, João-R ou Pedro-E.

\section{Resultados e discussão}

\section{Percepções dos pais acerca da funcionalidade do dever de casa}

Os dados revelaram que, para os pais, o dever de casa consiste numa atividade promotora de treinamento e retenção daquilo que o aluno aprendeu na escola, tal como sugere a fala a seguir: "Dever de casa não deixa de ser um treinamento do que ele [o aluno] aprendeu na sala de aula" (João-I). Como é possível notar aqui, supõe-se que o dever de casa é uma prática desejável. Já a fala de Pedro-R indica outras questões em termos pragmáticos: "A tarefa escolar (...) deveria ser mais uma fixação, mais um treinamento em casa, (...) do que foi feito em sala de aula (...) Então, acredito que o dever de casa é uma extensão, desde que seja bem trabalhado em sala de aula" (Pedro-R). O condicionante aqui sinalizado indica questionamentos acerca de seu uso, submetendo a validade da referida atividade a uma condição que está relacionada, de certo modo, à eficácia do ensino da escola. Curiosamente, esta condição, como se verá posteriormente, parece estar vinculada à questão da autonomia que os pais parecem desejar que os filhos alcancem, a fim de que possam realizar a tarefa independentemente da ajuda familiar.

Em relação ao aspecto funcional do dever de casa, a literatura sugere que esta atividade é vista, tradicionalmente, como um procedimento de ensino capaz de garantir reforço, fixação e preparação para aulas e provas, por meio de leituras ou de exercícios (Carvalho, 2004), além de também ser concebida como atividade facilitadora da retenção e compreensão de determinado conteúdo programático (Cooper, \& Valentine, 2001). Em consonância com a literatura, os resultados indicam que as percepções dos pais acerca da funcionalidade do dever de casa, de fato, estão relacionadas à questão do rendimento escolar, apesar dos sentimentos negativos que permeiam o envolvimento nesta tarefa.

A literatura revela outros indicadores dessa visão, conforme mostraram os resultados aqui apresentados, facilitando a compressão em torno da valorização e legitimação da referida atividade pelos pais, conforme mostram os estudos de Cooper e Nye (1994). Os autores sugerem que o reconhecimento do valor pedagógico da tarefa escolar nos dias atuais remonta a uma crença do início do século $X X$, que via o cérebro como um músculo que deveria ser exercitado mentalmente. Daí a aceitação quase espontânea de que a tarefa escolar contribui para a fixação e retenção de conteúdos pedagógicos. Assim, compreende-se que os pais percebem a tarefa escolar como um condicionante do sucesso acadêmico no processo de escolarização dos seus filhos.

\section{Percepções dos pais em relação aos sentidos que os filhos atribuem à tarefa escolar}

Na categoria "Percepção positiva" destacou-se a seguinte fala: "Ela - referindo-se à filha - pelo jeito que ela faz, ela faz com muito carinho e com muita atenção a tarefa de casa. Então, pelo jeito que ela faz, ela só pode gostar. E ela faz com muito cuidado, e leva visto de todas as tarefas para casa" (Alice-R). O sentido positivo relacionado ao dever de casa apareceu uma única vez, na fala de uma responsável de uma aluna com rendimento "regular", embora pudesse se esperar esse tipo de associação por parte de pais de alunos com rendimento "bom" e "excelente". Estes resultados podem indicar que a tarefa escolar está longe de ser uma atividade prazerosa para os alunos.

A "Percepção negativa" revelou-se por meio de uma quantidade razoável de falas de responsáveis. Os relatos indicam que os participantes percebem nos filhos comportamentos de fuga diante da tarefa, como meio de eximir-se do cumprimento desta. Um desses comportamentos ficou evidenciado quando o responsável relatou que o filho omite se tem ou não dever de casa, como indica o exemplo a seguir: "As tarefas que vão pra casa, ele esconde dentro do computador, sabe, dentro da impressora" (Vitor-l).

Os pais relataram que a percepção negativa também é reforçada pela manifestação de comportamentos que favorecem o adiamento da execução da referida atividade, ou seja, os filhos parecem deixar sempre a realização da tarefa para depois, como é possível notar nestas falas:

"Muitas vezes deixam pra fazer na sala de aula. Então eles acham que é um verdadeiro saco" (Lúcia-B). 
"Pelo comportamento dele, ele não gosta, não. Deixa sempre pra depois. Dá a entender que ele não gosta muito, não" (João-I).

"O meu filho odeia tarefa escolar. É normal. Acha um saco" (Susana-R).

Como se pode depreender das falas acima, para os pais, os adolescentes demonstram não gostar das tarefas escolares. Vale ressaltar que o relato da participante Susana-R revela que esta considera "normal" a aversão do filho em relação à atividade, parecendo não levar em conta que o aparente tédio gerado na ação de realizar a tarefa pode, de algum modo, comprometer sua eficácia e, por conseguinte, o próprio desempenho escolar do aluno.

As percepções negativas que os pais acreditam que os filhos têm em relação à tarefa escolar configuram-na como atividade desprovida de prazer, ou como tarefa realizada apenas sob pressão, não havendo tomada de iniciativa. É interessante notar, ainda, que estas percepções negativas foram atribuídas a alunos com rendimentos que variavam de "insuficiente" a "bom", o que leva a supor que nem mesmo os rendimentos satisfatórios, como é o caso dos alunos com conceito "bom", garantem comportamentos típicos de dedicação e de prazer na execução da referida atividade. Vale ressaltar que, dentre os participantes da pesquisa, apenas um dos pais tinha filho com rendimento "excelente", enquanto cinco tinham filhos com rendimento "regular", três tenham adolescentes com rendimento "bom" e três pais tinham filhos com rendimento "insuficiente".

Comparando-se as duas percepções de sentidos opostos de tarefa escolar encontradas nas falas, têm-se dois perfis de alunos: de um lado, o aluno que, de forma pontual, dedica-se ao cumprimento das obrigações para com as tarefas, e de outro, um aluno que apresenta comportamento de repulsa e aversão e para quem a tarefa escolar constitui-se como perda do tempo a ser dedicado ao lazer.

Estudos sugerem que, a despeito de a tarefa escolar nem sempre alcançar as metas a que se propõe, como aquelas relacionadas à eficácia na aprendizagem, ainda assim, nem sempre provoca questionamentos por parte da sociedade (Rosário, \& cols., 2008; Soares, 2011). Diante disso, seria pertinente verificar, em face dos resultados demonstrados, até que ponto o nível de insatisfação dos alunos diante da tarefa estaria comprometendo os objetivos da tarefa. Assim, o nível de insatisfação dos adolescentes diante da realização do dever de casa, conforme constatado, pode estar de algum modo, desfavorecendo a própria aprendizagem.

A dosagem de responsabilidade entre pais e escola, a falta de tempo e de preparo dos pais para o devido acompanhamento, a tensão gerada na relação entre pais e filhos no momento da realização da tarefa, a quantidade de tarefas, o significado do dever para os alunos, a questão de gênero, entre outros (Carneiro, 2010; Carvalho 2004; Nogueira, 2005; Paula, 2000; Resende, 2011; Rosário, \& cols., 2008), foram alguns temas discutidos a partir dos resultados encontrados. De modo geral, esses resultados trazem à tona o caráter polêmico existente por trás das investidas de envolvimento dos pais na tarefa escolar, evidenciando dificuldades pouco discutidas ou mesmo, muitas vezes ignoradas e transformadas em consenso.

\section{Percepção dos pais em relação à participação na vida escolar dos filhos}

A "Participação Direta" na vida escolar apareceu de forma nítida nas verbalizações, a exemplo dos seguintes relatos: "Olha, gente, eu sou uma mãe muito participativa, eu tô sempre aqui. Eu procuro falar com qualquer professor, eu não espero reunião" (Maria-R). Além da preocupação em se fazer presente na instituição de ensino, como forma de acompanhar o desenvolvimento escolar do filho, algumas falas expressaram a preocupação dos pais em garantir a participação através da supervisão e acompanhamento no dever de casa do filho, como sugere o exemplo a seguir: “(...) eu sou presente em tudo. Se eu chegar em casa dez horas da noite, morrendo de cansada, eu vou olhar os cadernos, se tá feito o dever de casa e se tem alguma coisa a mais" (Elane-B). Por outro lado, ao mesmo tempo em que se observou a "Participação direta" sendo apontada como um fator positivo, a fala induz a percebê-la como atividade que demanda um esforço extra, ou mesmo um elevado nível de investimento. Carvalho (2004) sustenta que a família acaba sendo vitimada por conta do envolvimento na tarefa escolar, tanto incentivado pelas escolas, que parecem desconsiderar as adversidades enfrentadas pelos pais, como a que foi revelada no conteúdo da fala acima.

As falas que ilustraram a "Participação indireta" indicaram preocupação com as implicações que certos estilos de envolvimento dos pais podem acarretar para o desenvolvimento dos filhos. Como exemplo desses estilos foi apontada a interferência excessiva dos pais, a ponto de comprometer o desenvolvimento de atitudes necessárias, não apenas à vida acadêmica, mas, sobretudo, à vida como um todo. "A participação deve interferir até certo limite. Influencia, mas não deve ser excessiva, senão eles acabam não tendo iniciativa própria. (...) Eu sou aquele camarada que tenta incentivar ele. Eu digo: 'Olha aí teus estudos”' (João-I).

Assim, foi possível perceber a inclinação desses participantes a incentivar os filhos a desenvolverem comportamentos de autonomia e independência, como é possível observar nesta fala: "A participação excessiva prejudica muito. Esse ano (...), dei responsabilidade pra ele e tá sendo maravilhoso" (Ana-B). Tal inclinação também se manifesta, de forma pontual, ao assinalar o posicionamento contrário em relação ao acompanhamento escolar com professor particular, como ilustra esta verbalização: "Ele não tem professor particular e eu boto a responsabilidade em cima dele" (Ana-B).

Manifestada por relatos que não necessariamente valorizam a presença física do responsável na escola, a "Participação indireta" pareceu dar indícios de que, mesmo não lidando com as questões mais práticas, como ir à 
escola para coletar informações sobre o filho ou sentar-se junto com ele para realizar a tarefa escolar, ainda assim ela é considerada uma forma de participação. As falas a seguir, fazem esta sugestão:

"Eu não sou uma mãe, assim, 100\% participativa, principalmente na escola. Eu não gosto de vir no colégio (...) Mas, assim... eu sou participativa na minha casa. Também dou todo o suporte pra ele fazer trabalho" (Susana-R)

“(...) Eu não reviso tarefa, não faço tarefa. Acompanho todos os trabalhos (...), mas eu realmente não acompanho assim, de perguntar aos professores se tá tudo bem. (...) Eu participo na cobrança. Vejo as notas, peço o boletim (...) (Pietra-E).

Desse modo, o envolvimento parental foi concebido por comportamentos de incentivo e estímulo, por atitudes que ofereçam suporte estrutural para o cumprimento das obrigações escolares ou, ainda, por um tipo de participação que envolve o incentivo à autonomia. $O$ investimento financeiro nos estudos, também compreendido como forma de incentivo e de apoio, aparece como outra forma de participação indireta, como revelou o relato do participante Camila-I: "Olha, eu não sei se a minha participação é 100\%, mas que eu ajudo, ajudo. Eu trabalho de manhã e ele estuda à tarde. Então, como eu pago o colégio, que é caro, e pago o professor de reforço, eu já deixo pros dois" (Camila-I). Esta fala sugere que o fato de o pai disponibilizar recursos financeiros para pagar os estudos do filho constitui-se como uma forma indireta de participação na vida escolar, ou seja, um tipo de envolvimento considerado válido.

Diante dos resultados encontrados, o envolvimento parental no dever de casa tem sido usualmente incentivado, apesar da ambivalência de sentimentos provocados nos pais que não conseguem corresponder a contento às obrigações que lhes são impostas (Rosário et al., 2008). A prescrição das atividades escolares no espaço doméstico parece ocorrer dando-se pouca atenção à engrenagem socioeconômica que configura as famílias contemporâneas, em que tanto a figura do pai como a da mãe, diante das exigências do mercado de trabalho, não dispõem do tempo que o acompanhamento exige. A esse respeito, não é de se estranhar que os pais revelem uma grande expectativa de que os filhos adquiram autonomia na realização da tarefa. O desvelamento dessas implicações, de algum modo, redimensionaria não apenas a maneira de pensar sobre o papel da escola, mas também a relação desta com a família, incluindo aí as campanhas em prol da adesão do dever de casa.

\section{Sentimentos dos Pais acerca da Realização da Tarefa Escolar}

A categoria "Contra a tarefa" reuniu falas que revelaram a presença de algumas adversidades postas no dia a dia, especificamente relacionadas à falta de tempo e de disponibilidade dos pais, dificultando a possibilidade de conciliar o envolvimento na referida atividade, como se vê nos exemplos a seguir:

"Bom, eu não concordo muito com tarefa escolar, porque eu acho que é trabalho para os pais (...). Primeiro, que nem todos os pais estão em casa; às vezes, a criança fica só. No meu caso, trabalha eu, trabalha meu marido, não tem ninguém em casa, ele fica só (...) Eu sou contra tarefa escolar, porque o aluno tem que fazer as coisas na escola" (Ana-B)

\footnotetext{
"A questão da pesquisa, muitas vezes quando é levada pra casa, torna-se um trabalho para os pais fazerem, muitas das vezes" (Lúcia-B).
}

Nota-se que as configurações sociais das famílias contemporâneas, em que tanto a figura paterna quanto a materna contribuem para o sustento da casa, parecem favorecer a emergência desse tipo de sentimento aversivo em relação ao dever de casa. É evidente a preocupação com o fato de não se poder ajudar o filho na tarefa. Tal sentimento parece estar relacionado ao incômodo provocado pela transferência de responsabilidade repassada pela escola, sinalizando que os relatos parecem indicar que a tarefa escolar, da forma como é posta pela escola, representa carga extra de trabalho para os pais.

A categoria "Insegurança" reuniu falas que expressaram dificuldades em acompanhar o conteúdo acadêmico ministrado na escola: "Por exemplo, matemática, eu tô em casa, eu já acompanho ele pouco. É porque eu também acho difícil" (Maria- $R$ ).

Outro aspecto que pôde ser observado refere-se ao dilema enfrentado pelos pais na maneira de conduzir o aprendizado em casa. De acordo com a fala da participante Rosana- $R$, as estratégias de ensino adotadas pelos professores são diferentes daquelas que os pais utilizam: "Ainda tem isso, às vezes, a gente quer ensinar e não é como o professor ensinou" (Rosana-R). Para a família, esta falta de sintonia pode gerar sentimentos confusos nos filhos, podendo prejudicar sua aprendizagem.

A despeito da visão favorável de Corno e Xu (2004) acerca do envolvimento dos pais na tarefa, segundo a qual os pais não precisam ter amplo conhecimento para auxiliar o filho, os resultados encontrados permitiram fazer algumas observações. Talvez não seja, de fato, necessário um vasto conteúdo acadêmico por parte dos pais, mas o fato de os pais não dominarem alguns conhecimentos específicos dentro de cada disciplina ensinada na escola pode influenciar o tipo de acompanhamento realizado em casa. Tal questão pode influenciar tanto o desempenho acadêmico dos alunos como os sentimentos de insegurança dos pais diante da dificuldade de acompanhamento.

Curiosamente, destaca-se que esses mesmos dados revelaram uma contradição em relação à suposição de que pais com nível de escolaridade superior poderiam interferir 
de forma mais positiva e eficaz na hora da realização da tarefa, como sugerem Epstein, \& Voorhis (2001). Os autores associaram positivamente nível de escolaridade alto dos pais e maior envolvimento parental, como decorrência de melhor preparo para esse tipo de envolvimento e das expectativas em relação ao futuro dos filhos. Por outro, embora os pais participantes da pesquisa tivessem, em sua maioria, nível superior, ainda assim demonstraram dificuldades em acompanhar o conteúdo acadêmico. Vale ressaltar que, dentre os pais que participaram do grupo focal, $77,8 \%$ possuíam nível superior, contra 22,2\% que não o possuíam. Quanto às participantes Maria-R e Rosana-R, que evidenciaram ausência de repertório acadêmico para esse tipo de acompanhamento, ambas possuíam nível superior. Portanto, é possível que o nível de escolaridade dos pais não deva ser considerado como variável preditiva de preparo e, consequentemente, de eficiência do acompanhamento parental na vida escolar do filho, embora, em conjunto com outras variáveis - como a rotina, o funcionamento emocional e a dinâmica familiar possa ser uma característica auxiliar nesse processo.

\section{Considerações finais}

Os resultados encontrados neste estudo revelaram que a percepção que os pais têm sobre a tarefa escolar é de que a referida atividade faz parte da dinâmica acadêmica dos alunos, sendo necessário, desse modo, corresponder às investidas de envolvimento exigidas pela escola. A despeito dessa visão, os pais revelaram, também, sentimentos negativos que permeiam este envolvimento no dia a dia, indicando a necessidade de discutir o aparente consenso em torno da prescrição da tarefa.

A pesquisa contribuiu para revelar uma série de nuanças que envolvem a tarefa escolar, uma vez que a referida atividade não está circunscrita apenas ao sistema escolar, pois os dados indicaram a necessidade de se pensar nas relações, implicações e consequências em outros sistemas que podem influenciar a eficácia de sua realização. Desse modo, o dever de casa se apresenta como dinâmica que movimenta outros sistemas além da própria escola, como a família, por exemplo.

Supõe-se que o incentivo ao envolvimento parental, quando realizado sem considerar as dificuldades que subjazem à tarefa escolar, pode estar omitindo, entre outros elementos, a própria dificuldade da escola em garantir o seu papel, em relação tanto às questões acadêmicas quanto aos aspectos que envolvem o desenvolvimento do indivíduo, como aqueles relacionados à autonomia, à proatividade e à autorregulação do aluno.

Diante da dificuldade de garantir a participação dos pais, por eles não disporem de condições para isso, verificou-se a necessidade de realizar outros encontros com o grupo focal. A reflexão que o estudo propiciou indica a necessidade de desenvolver discussões que considerem a qualidade da interação entre pais e filhos no envolvimento parental.
Não se pretendeu com essa pesquisa levantar protestos contra ou a favor do dever de casa, apenas favorecer o esclarecimento de que sua existência e consequente repercussão no desenvolvimento do aluno estão atreladas a todas as adversidades típicas da vida contemporânea. É nesse sentido que se justifica o repensar da dinâmica do dever de casa.

\section{Referências}

Bardin, L. (1995). Análise de conteúdo. Lisboa: Edições 70.

Carneiro, B. V. (2010). Dever de casa, algumas reflexões. Revista Educação, 2, 34-46. Recuperado em 10 de fevereiro de 2013. Disponível: http://www.anchieta.br/Unianchieta/revistas/educacao/ publicacoes/revista_educacao_02.pdf\#page=36

Carvalho, M.E.P. (2004). Escola como extensão da família ou família como extensão da escola? Revista Brasileira de Educação, 25, 94-104. Recuperado em 07 de janeiro de 2013. http://www. anchieta.br/Unianchieta/revistas/educacao/publicacoes/revista_ educacao_02.pdf\#page=36

Charlesworth, L. W., \& Rodwell, M. K. (1997). Focus group with children: A resource for sexual abuse prevention program evaluation. Child Abuse \& Neglect, 21, 1205-1216.

Cooper, H., \& Nye, B. (1994). Homework for student with learning disabilities: The Implications of research for policies and practice. Journal of Learning Disabilities, 27, 470-479.

Cooper, H., \& Valentine, J.C. (2001). Using research to answer practical questions about homework. Educational Psychologist, 36, 143-153.

Corno, L., \& Xu, J. (2004). Homework as the job of childhood. Theory into Practice, 43, 227-33.

Epstein, J.L., \& Van Voorhis, F.L. (2001). More than minutes: Teacher's roles in designing homework. Educational Psychologist, 36, 181-190. Recuperado em 10 de janeiro de 2013. Disponível: http://555seminar.pbworks.com/f/ Epstein+\%26+Van+Voorhis+(2001).pdf

Grolnick, W.S., \& Slowiaczec, M.L. (1994). Parents involvement in children's schooling: A multidimensional conceptualization and motivational model. Child Development, 65, 237-252.

Hoover-Dempsey, K.V., Battiato, A.C., Walker, J.M.T., Reed, R.P., \& Jones, K.P. (2001). Parental involvement in homework. Educational Psychologist, 36, 195-209.

Nogueira, M. A. (2005). Família e escola na contemporaneidade: Os meandros de uma relação. Educação e realidade, 31(2), 155-170. Recuperado em 04 de março de 2013. Disponível: http://seer. ufrgs.br/index.php/educacaoerealidade/article/viewFile/6850/4121 
Paula, F. A. (2000). Lições, deveres, tarefas, para casa: velhas e novas prescrições para professoras. Dissertação de mestrado. Recuperado em 03 fevereiro de 2013: Disponível: http://www. bibliotecadi gital.unicamp.br/document/?view=vtls000214661

Resende, T. F. (2011). Dever de casa: questões em torno de um consenso. Projeto Integrado de Pesquisa do Observatório Sociológico Família-Escola. Recuperado em 12 de março de 201.: Disponível: http://www2.unifap.br/gpcem/files/2011/09/GT14Dever-de-casa.pdf

Rosário, P., Baldaque, M., Mourão, R., Nuñez, J. C., GonzálezPienda, J. A., Valle, A., \& Joly, C. (2008). Trabalho de casa, auto- eficácia e rendimento em Matemática. Revista Semestral da Associação Brasileira de Psicologia Escolar e Educacional, 12, 23-35. Recuperado em 27 de fevereiro de 2013. Disponível: http:// www.scielo.br/pdf/pee/v12n1/v12n1a03.pdf

Soares, E. R. N. (2011). O dever de casa no contexto da avaliação das aprendizagens. Dissertação de mestrado. Recuperado em 18 de março de 2013. Disponível: http://repositorio.bce.unb.br/ bitstream/10482/7946/1/2011_EnilviaRochaMoratoSoares.PDF

Zimmerman, B. J., \& Risemberg, R. (1997). Becoming a self regulated writer. A cognitive perspective. Contemporary Educational Phychology, 22, 73-101.

\section{Sobre as autoras}

Ana Patrícia de Oliveira Fernandez (apsol2@hotmail.com / apsol0204@gmail.com).

Mestre e Doutoranda do Programa de Pós-Graduação em Teoria e Pesquisa do Comportamento - UFPA.

Fernando Augusto Ramos Pontes (fernando.pontes@pesquisador.cnpq.br).

Prof $^{\circ}$ Dr. do Programa de Pós-Graduação em Teoria e Pesquisa do Comportamento - UFPA.

Simone Souza Costa e Silva (symon.ufpa@gmail.com).

Profa Dra. do Programa de Pós-Graduação em Teoria e Pesquisa do Comportamento - UFPA.

Mayara Barbosa Sindeaux Lima (mayarasindeaux@gmail.com).

Mestre em Teoria e Pesquisa do Comportamento - UFPA.

Cláudia Oliveira dos Santos (claudiacardim@hotmail.com).

Mestre em Teoria e Pesquisa do Comportamento- UFPA.

Este estudo obteve apoio da CAPES e originou-se da dissertação de mestrado intitulada "Envolvimento Parental na Tarefa Escolar: Um Estudo Realizado com Adolescentes", de autoria de Ana Patrícia de Oliveira Fernandez, cujos dados foram coletados na cidade de Belém-PA, respeitando todos os parâmetros éticos de pesquisas com seres humanos. 